\title{
Culture-Sensitive Communication in Applied Developmental Research
}

\author{
Robert Serpell \\ University of Zambia, Lusaka, Zambia
}

\section{Keywords}

Africa - Culture - Early childhood education · History .

Perspectivism · Policy · Theory

\begin{abstract}
Communication about child development between persons with different cultural preoccupations requires that author and audience agree without coercion on how to connect their perspectives. Western cultural hegemony persists in many international fora under the guise of "globalization," giving rise to systematically distorted communication in ways that do epistemological violence to indigenous cultural models in Africa. The dominant paradigm of public basic schooling is sustained by institutionalized path dependency and construes educational success as extracting the learner from her community of origin. Consensus-building within a framework of mutually respectful communication involves bridging, coordination or fusion. Societal progress is a different kind of "development" than ontogenesis. A given cultural group's developmental niche for its children is part of a chronosystem that changes over the course of history. An individual's transactions with significant others are embedded in a complex and dynamic sociocultural system, to which programming of early childhood education should respond.

(c) 2021 S. Karger AG, Basel
\end{abstract}

\section{Piaget's Universalistic Theory}

Jean Piaget offered, over the course of his profoundly influential body of work, a seminal account of human development that portrays the child as an acting person whose mode of thinking is informed by a set of beliefs grounded in experience. The child's understanding gradually evolves from reflex responses, via representation, into an implicit theory of knowledge. Piaget combined naturalistic observation of his own children with interactive experiments designed to reveal the reasoning underlying their behavior at successive stages of development. And he constructed an elaborate theory to explain how the child, like an investigator in the tradition of Western empirical science, explores the world around her, testing hypotheses and revising them in the light of evidence, with a view to improving the adaptive fit between her understanding and the objective world (Piaget, 1970).

Piaget's theory introduced the explanatory concepts of adaptation as a balance between assimilation and accommodation, structures d'ensemble and décalages as a framework for describing the child's cognition across multiple domains, and the tension between equilibration and disequilibration as fueling ontogenetic change. Research inspired by the theory has focused productively on a number of different facets, including refining methods of elic- karger@karger.com www.karger.com/hde

(c) 2021 S. Karger AG, Basel

Karger"
Robert Serpell

Universityof Zambia

Department of Psychology, Great East Road

Lusaka 10101 (Zambia)

robertNserpell@gmail.com 
iting evidence of the child's implicit theory of knowledge and formalizing the structural account of that implicit theory. One strand of research has been devoted to the question of the theory's generalizability.

Following the modern tradition of empirical science, researchers have sought confirmation of the theory by replicating Piaget's data collection procedures with larger samples of children, including schoolchildren in Switzerland, in other Western, industrialized societies, and in societies of the Majority World (Kagitcibasi, 1996). Of special interest in the Majority World has been the question of whether Piaget's theory is generalizable to the development of children growing up outside the direct influence of Western culture mediated by the increasingly standardized model of institutionalized public basic schooling (IPBS; Serpell \& Hatano, 1997). Dasen's (1972, 1977) authoritative reviews concluded that:

(a) the empirical evidence generally confirmed the universal generalizability of Piaget's interpretation of the developmental transition from preoperational to concrete-operational thinking, but

(b) suggested that variations across different sociocultural settings in the experiences afforded to children significantly influenced the age at which that transition occurred, and

(c) suggested that the mode of understanding conceptualized by Piaget as formal operational thinking only arises in the development of children raised in sociocultural settings where they are exposed to the modern, Western model of science.

These conclusions are open to a number of different meta-theoretical interpretations. Three dimensions of diversity arise in the context of a research agenda focused on generalizability: subject database, authors/investigators and audiences (Serpell, 1990). Several critical reviews have focused on the first two of these (e.g., Adair et al., 2002; Henrich et al., 2010). Much of the skepticism generated by this critical attention to the evidence base for generalizability has focused on the possibilities that (a) different sociocultural settings may cause children to develop differently, or that (b) investigators' design of their research may have been biased by their own primary childhood enculturation and/or their familiarity with, and commitment to, socialization practices prevalent in Western, educated, industrialized, rich and democratic (WEIRD) societies. In my view, while both of those limitations of the empirical evidence are probably significant, a more important source of bias has been the audience to which the published research findings have been addressed.

Culture-Sensitive Communication in

Applied Developmental Research
According to Habermas (1984), "communicative actors can achieve an understanding only by way of taking yes/no positions on criticizable validity claims" (p. 70). Claims that a verbal utterance is valid are of three kinds: (a) the objectivity claim that it fits with the objective world (propositional truth, effectiveness or instrumental success), (b) the normative appropriateness claim that it is right in the sense of according with social norms given the context of its utterance and (c) the sincerity claim that it genuinely expresses the subjective state of mind of the actor, that is, it is sincere or authentic (Habermas, 1984). The lifeworld (Lebenswelt) of a cultural tradition "stores the interpretive work of preceding generations" and comprises "normatively ascribed agreement" on some unproblematized, background convictions (Habermas, 1984, p. 70).

I shall argue in this paper that in order to apply developmental science in the field of educational policy and practice, rather than seeking evidence of universal generalizability, the focus of research should be on negotiation of communicatively achieved understanding among stakeholders in a shared agenda of supporting the development of individuals and promoting progressive social change.

\section{Communication between People with Different Cultural Preoccupations}

Explaining the behavior of another person is an attempt to communicate. The author of the explanation seeks to share with an audience an interpretation of why a subject acts in a particular way. All three positions in this communicative activity are occupied by one or more thinking, acting persons. Evaluating a psychological explanation can therefore be regarded as resting on the logical premise that any one of them could in principle be the subject of such an interpretation or the audience to whom it is addressed (Shotter, 1975; Serpell, 1990). Thus, if I were to propose that a particular preschool child we have been observing on a videotape (e.g., Tobin, Wu, \& Davidson, 1989) may be "exceptionally intelligent," the audience would be entitled to challenge my interpretation by asking "if you behaved that way, would you expect me to regard you as exceptionally intelligent?" (moving the author to the position of subject), or "what if I were to interpret that child's behavior as a sign of impaired intelligence?" (moving the author to the position of audience).

In my original formulation of this reflexive triangle, I represented the challenge of communicating about psy-

Human Development 2020;64:222-237 
chological functioning as the intersection of three spatial perspectives (Fig. 1). The three positions on the diagram arise from the logic of communication: an author addresses a speech utterance to an audience about a subject. The author identifies an ostensible subject as referent and proposes to the audience an interpretation of the behavior and mind of that subject, who also has a perspective of her own.

The perspectives symbolized by overlapping circles in Figure 1 should be interpreted not as socioemotionally neutral, static descriptions of the objective world but as representations of that world that are advanced as bids for representational interaction in which considerations of power and honesty are also at play. Drawing on that dynamic account of the reciprocal relations among the three positions that motivate psychological explanation, I propose to articulate in this paper an agenda for applied developmental research that places the goal of cooperative communication ahead of the goal of testing the generalizability of a particular theory.

The motivational context of action-oriented communication has been conceptualized by Harré and others in terms of positioning theory:

The significance of the actions that people carry out, including speech acts, is partly determined by the then-and-there positions of the actors. To have a footing in a social episode, one must at least have some recognized rights. What story-line is unfolding is mutually determined, pro tem unless challenged, by the speech acts people are heard to produce, and that in turn is mutually determined by the positions that they are taken to be occupying in the episode. Such positions are constituted by their assigned, ascribed, claimed, or assumed rights and duties to make use of the available and relevant discursive tools. (Harré et al., 2009, p. 8)

Thus, if an author's relation to the audience is construed by the participants as that of teacher to learner, evaluation of her utterances will be systematically different than if the two of them are friends, and different yet again if they are construed as master and servant. Furthermore, those relations are not static but are liable to change over the course of an episode of communication. For instance, in a conversation about planning for a young person's advanced education, a grandfather and granddaughter might focus their communicative stances differently with respect to the relative advantages of various study programs than with respect to the affordances of a modern communication device for maintaining future contact. The elder, more experienced participant might be accorded greater authority in the discussion of university curricula with a view to expanding the young-

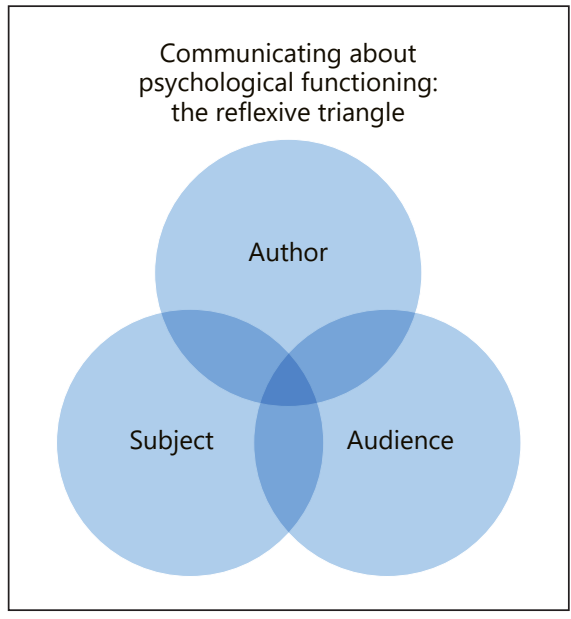

Fig. 1. The reflexive triangle for psychological evaluation.

er person's cognitive repertoire. But a situated change in position (with associated rights and duties) might be motivated by recognition of the grandchild's technological expertise, assigning her the role of teacher with the purpose of expanding the elder's cognitive repertoire and shifting him temporarily into the position of deferential audience: "Please show me how to configure my mobile phone to receive WhatsApp messages."

In the context of IPBS or of early childhood development care and education (ECDCE), a teacher who explains to a parent that their child's development is like the exploratory journey of an empirical scientist is implicitly seeking to bring the parent's cognition and behavior into harmony with the teacher's pedagogical agenda. For instance, advice in the form "he really needs to work on his time table (or on his spelling)" rests on the assumptions that:

(a) teacher and parent share a perspectival horizon of aspiring for the child's educational success,

(b) teacher knows better than parent what is required by the school curriculum, and

(c) parent is in a position to motivate the child's engagement in a particular activity, that is

(d) prescribed by teacher on the authority of her expertise about the curriculum.

In this context, a scientific theory of child development is deployed by the teacher as a legitimizing framework for the kind of social relationship among teacher, child and parent for which the teacher is a professional advocate.

What if those assumptions are not shared by a parent? What if she questions the validity of the advice? Given the conventional underwriting of assumptions (a) and (b) 


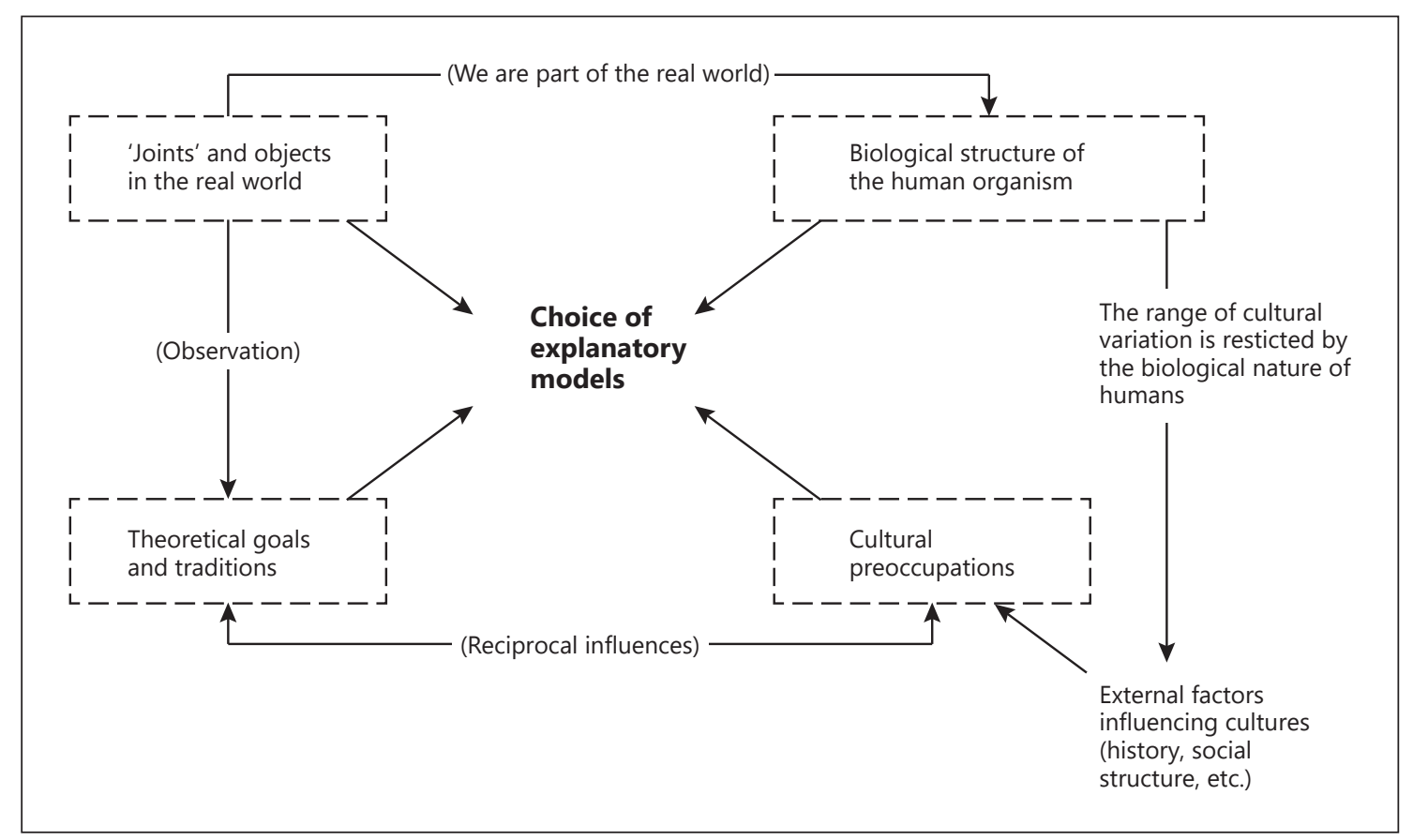

Fig. 2. Validation criteria for explanatory models.

and (d), they are difficult for a parent to challenge. She is more likely to complain that assumption (c) does not apply in this particular case, for example, because:

(i) the child is not responsive to the parent's attempts at motivation,

(ii) the parent feels inadequately prepared, given her lack of expertise, or

(iii) the parent has other priorities arising from economic and/or social factors.

\section{Resisting Cultural Hegemony}

The expertise of a teacher, a psychologist or some other professional is typically grounded in some kind of explicit theory, and laypersons often accord respect to the professional's opinion on the supposition that $\mathrm{s} / \mathrm{he}$ has derived that theoretical knowledge from an authoritative source such as a recognized scientific or professional institution. Within the forum of scientific discourse, scholars debating the validity of particular explanatory models derive their preference for a given model, not only from systematic observation of the real world, but also from less explicitly acknowledged criteria such as theoretical goals and traditions that are deeply imbued with broader cultural preoccupations of their society (Fig. 2).

Culture-Sensitive Communication in

Applied Developmental Research
While some of those preoccupations may be almost universally shared across the world's societies (e.g., the potential of modern information and communication technology, or the current hazards of global warming), others vary significantly across societies as a result of their prevailing social structures and their histories. Over the past two centuries, a confluence of technological, economic and political power has generated widespread Western cultural hegemony across the world (Apple, 1979). As noted above, the mainstream of psychological science, published in the most highly respected scholarly journals displays a predominance of studies conducted by culturally Western scholars on culturally Western population samples and addressed to an audience of reviewers and editors with Western cultural preoccupations. Much of the theoretical knowledge that recognized experts around the world derive from their professional education is grounded in that culturally biased, authoritative literature.

One pathway to correction of that hegemonic bias was described by Azuma (1984) in his account of the history of psychology in Japan as passing through several stages of progressive emancipation from Western culture. In his view, "a more generally valid psychology will emerge by identifying what is culturally specific in the mainstream psychology and adopting new concepts of general appli- 
cability from other cultures" (Azuma, 1984, p. 45). In the Philippines, Enriquez (1977) took a more radical position that gave rise to a nationwide movement Sikolohiyang Pilipino, grounded in the vocabulary of the indigenous Tagalog language. Sinha (1997) discussed various types and levels of "indigenization of psychology," "as a facet of worldwide concern for making knowledge culturally appropriate" (p. 131), noting that the topic had received most attention in the so-called "developing world," including India, China and Latin America.

In Africa, Nsamenang (1992) argued that the indigenous strand of the continent's triple cultural heritage (Mazrui, 1986) had been neglected by social scientists and policymakers with oppressive consequences. The nature of those consequences has been further elaborated by Oppong $(2015,2019)$, who contends that the effect of applying Western theory to the interpretation of African children's behavioral development has often been to do "epistemological violence:"

a practice that is executed in empirical articles and books in
psychology when interpretative speculations regarding results
implicitly or explicitly construct the "Other" as problematic.
The term epistemological suggests that these speculations are
framed as knowledge when in reality they are interpretative
speculations regarding data. The term violence denotes that this
"knowledge" has a negative impact on the "Other" and that the
interpretative speculations are produced to the detriment of the
"Other." The negative impact can range from misrepresenta-
tions and distortions to a neglect of the voices of the "Other,"
to statements of inferiority, and to the recommendations of
adverse practices or infringements concerning the "Other."
(Teo, 2008, p. 57)

To redress this neglect, Nsamenang set out,

to theorize key parameters of endogenous African practices and ethnotheories of child-rearing in eco-cultural context, to identify systematic strengths within that theoretical framework, and to advocate for their inclusion in the design of progressive interventions, such as education, health promotion, counseling, and early childhood care and education. (Serpell, 2019, p. 1)

The three-way validation scheme proposed by Habermas (1984) arose from his search for a corrective to what he earlier termed "systematically distorted communication" (McCarthy, 1978, pp. 93-125). The hazard of such systematic distortion confronts not only debates within academia, it also constitutes a profound challenge to African professionals in their communication with indigenous clients looking to them for guidance on how best to educate their children. Reaching a genuine understand- ing requires that the parties agree without coercion (Habermas, 1984). Yet, as Ejuu (2012) points out, early childhood education (ECE) curriculum developers and planners in Africa seldom refer to parental goals or aspirations for their children. Indeed, when those goals are mentioned, they are often cast as a source of resistance to be overcome under the heading of superstition, naivete or ignorance leading to practices that amount to neglect or abuse.

The coercion that sustains systematic distortion of communication between professional educators and children's families in Africa is rooted in the institution of schooling, which in many ways defines success in terms of extraction of the child from his or her community of origin. This extractive definition of success in IPBS in Zambia (Serpell, 1999) has close parallels in many other contemporary African nations.

Because of the dominance of the IPBS model, the plausible concept of ECDCE as preparing young children for education later in life is often oversimplified as preparation for coping with the restrictive demands of formal schooling (sitting still and paying attention to instruction) and acquisition of particular foundational skills (e.g., comprehension of the language of instruction, counting, drawing, letter recognition). (Serpell \& Mukela, 2019, p. 145)

International treaties and conventions designed to maintain peaceful coexistence between groups with differing opinions and practices call for negotiation grounded in some kind of reciprocity. Habermas' (1975) conceptualisation of the "ideal speech situation" (p. 113) posits an overriding principle of egalitarianism in which any and every discourse move can in principle legitimately be made by any participant in the conversation. But, as Shweder et al. (1990) have argued, such egalitarianism may be grounded in the Western cultural metaphor of interpersonal relationships as a market, whereas other cultures may prefer the metaphor of a hierarchy, where ascribed roles permit different discourse moves according to position. Invoking positioning theory, the ideal speech situation can be understood as one in which participants agree to adopt relevant positions from which to exchange and share ideas.

Thus, when an expert consultant recruited from a prestigious Western institution offers technical guidance to "lay" Third World policymakers about the best way to achieve the latter's stated goals, we might construe the author as adopting the stance of teacher while more or less consciously pursuing a latent master-servant agenda of shifting the cognition and behavior of local policymakers towards greater 
compliance with a hegemonic cultural formulation of societal progress. And a local or even indigenous expert recruited to advise the national government or another intervention agency runs the risk of inadvertently legitimizing that agenda, unless they explicitly distance themselves from hegemonic formulations of scientific evidence.

\section{Consensus-Building Strategies: Bridging, Coordination and Fusion}

A precondition for building bridges between contrasting cultural groups is some kind of mutual respect. A bargaining strategy for peaceful coexistence calls for each side to make minimal reciprocal concessions: "You do it your way; I'll do it mine." This strategy is widely endorsed in cosmopolitan settings where freedom of religious belief is extended to tolerance of such practices as dietary restrictions and styles of attire. The next step towards consensus-building is coordination, which goes beyond tolerance of differences to acknowledge domain-specific strengths: "Your system is really good for $\mathrm{X}$ (e.g., music, athletics); mine is really good at $\mathrm{Y}$ (e.g., mathematics, administration). By coordinating our efforts, we can complement one another's strengths for the benefit of society as a whole." Finally, there is the possibility of fusion, where territorial boundaries of ownership are transcended, and members of different communities agree to share and integrate cultural resources. This strategy includes translation (a cognitive activity that rests on the premise of some kind of equivalence), code-switching (Gumperz, 1982), translanguaging (García \& Wei, 2012) and other forms of cultural hybridity.

\section{Bridging}

Students enrolled in advanced programs of education in Africa

often appear to compartmentalize their thinking about traditional cultural practices and the beliefs that inform them in such a way that they have little or no opportunity to reflect on how those elements of their cognitive repertoire relate to the curriculum content of their study programmes. They deploy their indigenous funds of knowledge (Moll et al., 2005) in contexts such as family funerals and visits to their family's rural ancestral home, but exclude them from the range of resources they bring to bear on topics addressed in their classes. Project assignments that require students to engage with the world outside the walls of the campus are conducive to situated learning and afford students opportunities to compare and integrate academic theories with indigenous interpretations of experience. (Serpell, 2007, pp. 45-46)
Reflecting on the outcomes of such attempts at the University of Zambia to bridge between orthodox Western higher educational practices and an African sociocultural context, I noted that

the benefits of a well-designed and executed university student project may extend well beyond those experienced by individual students, to include public appraisal of universities as engaged and valuable resources for the wider society, and interinstitutional linkages that afford mutual complementary enrichment of the institutions, and economies of scale for providing students with productive learning experiences. (Serpell, 2007, p. 41)

The developmental outcomes for students were mixed:

Evaluation of student performance in such projects faces a tension between the rigorous application of methodological principles and the generation of valid interpretations of local phenomena. One reason for this tension is that the phenomena studied in projects often lie beyond the cutting edge of the formal discipline's research endeavours so that there is little of direct relevance to the project in the published literature. (Serpell 2007, p. 43)

Academic faculty willing to address that challenge stand to benefit "by discovering limitations in their own disciplinary training and in the theories and methods that they bring to the process of curriculum design" (Serpell, 2007, p. 43).

\section{Coordination}

Disciplined communication between culturally contrasting perspectives on a given topic requires a shared core of beliefs and some shared standards of truth and inference. Building on Gadamer's (1975) hermeneutical analysis of translation and Lukes' (1982) defense of perspectivism, I have proposed a dynamic approach to crosscultural communication about human development as negotiating the middle ground between ostensible referents ("in the physical world of enduring objects and persons linked by a system of push-pull causality"; Horton, 1982) and shared abstract, epistemological horizons (Serpell, 2006). Figure 3 illustrates how this approach might be used for coordinating the psychological explanations proposed by Piaget in terms of "concrete operational thought" and by Nsamenang in terms of "social apprenticing." In Nsamenang's (2006) Africentric theory of social ontogenesis, the major developmental task of the second phase, social apprenticing, roughly corresponds with 


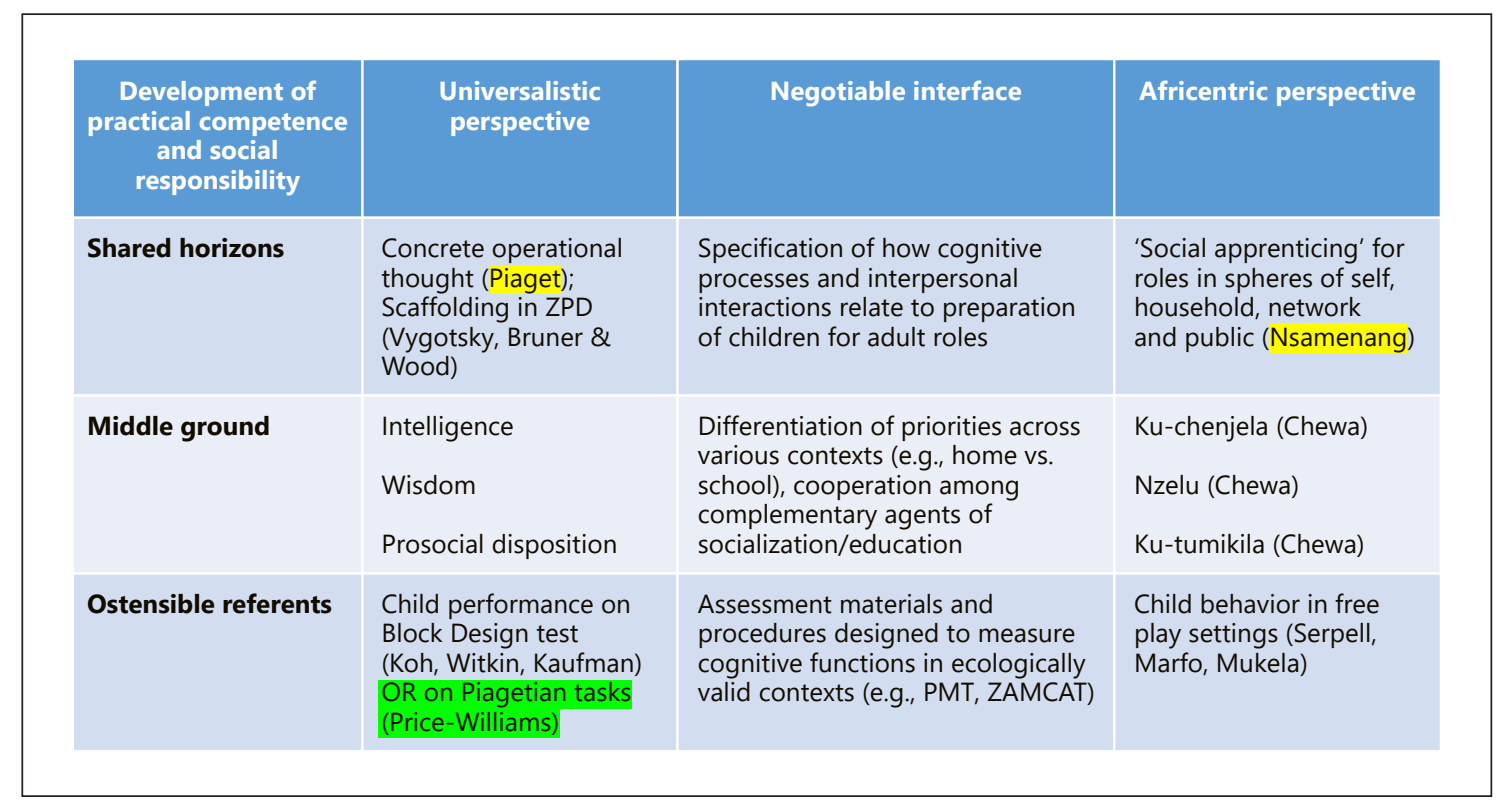

Fig. 3. Integrative possibilities for coordination or fusion. PMT, Panga Muntu Test; ZAMCAT, Zambia Child Assessment Tool.

preadolescent childhood. Its principal developmental task is to recognize, cognize and rehearse social roles that pertain to four hierarchical spheres of life: self, household, network and public. Adult delegation of responsibility to children of this age for care and socialization of younger children serves the function of priming the emergence of social responsibility.

The interface between the two theories could be negotiated at the level of abstract horizons in terms of complementarity, by specifying how cognitive processes and interpersonal interactions relate to preparation of children for adult roles. And, at the level of ostensible referents, consensus could in principle be established on the design of assessment materials and procedures to measure cognitive functions in ecologically valid contexts, drawing on the design of Piagetian and other tasks prevalent in Western psychometric instruments and adapting them to resonate with naturalistic observations of child behavior in free play settings of African ecosystems (e.g., Marfo \& Biersteker, 2011; Mukela, 2013). Some elements of this approach have been deployed in the development in Zambia of locally adapted tests such as the Panga Munthu Test (PMT) and the Zambia Child Assessment Tool (ZAMCAT) (Matafwali \& Serpell, 2014).

But how should negotiation proceed in the middle ground between those two levels in explaining the development of practical competence and social responsibili- ty? Key explanatory constructs in mainstream universalistic theory include intelligence, wisdom and prosocial disposition, whereas (to take one example of an Africentric perspective), Chewa culture offers the constructs of Nzelu, ku-Chenjela and ku-Tumikila (Serpell, 1993). Sternberg's (2000) universalistic theory might be deployed to equate Nzelu with wisdom and ku-Chenjela with intelligence. But according to our expert informants on Chewa traditional culture, such a sharp dichotomy would be inappropriate: for, to designate a child as waNzelu, calls for evidence that s/he is both wo-Chenjela and wo-Tumikila. A way forward suitable for preparation of ECE professionals to work in a rural Chewa community setting might be to differentiate priorities across various contexts (e.g., home vs. school), and promote cooperation among complementary agents of socialization/education (e.g., parents and ECE teachers).

\section{Fusion}

The outcome of such negotiations of meaning may be expected to include enhanced reciprocal respect within each culture for the ideas and practices of another cultural group. Coordination between them may take the form of acknowledging complementary insights, or in some cases cross-cultural appropriation. Importing a 
term from another language may signify recognition that it is not directly translatable into the vocabulary of the host language, as seems to be the case for the French term ambience, the German term zeitgeist, or the Yiddish term chutzpah for which no clear equivalent exists in core English vocabulary. In Zambia's multilingual cities, cosmopolitan residents are expected to engage in translanguaging, a practice that was once stigmatized as disrespectful of both languages' standards but is now so popular that it is leveraged by commercial advertising and political campaigning.

As with the topic of multilingualism, cultural diversity can be construed as a feature of a social group or as a feature of an individual's cognitive repertoire. One strategy open to a bicultural individual is situational code-switching. A Zambian parent who appreciates the rationale for each of two contrasting perspectives may systematically alternate between them in accordance with the affordances of different contexts. She may, for instance, incorporate her 6-year-old child in domestic routines of food preparation and infant care at home, but also invest financially in fees for a private nursery school and the purchase of storybooks to share with the child at bedtime. The cognitive repertoire that informs such a pattern may be quite firmly compartmentalized, allowing the contrasting perspectives to coexist with little or no conflict. But in some cases, the borders between compartments may be permeable, giving rise to a reflective search for more active reconciliation. (Serpell, 2018, p. 59)

While the presentation of contrasting perspectives in Figure 3 emphasizes contrasts, especially in the middle ground, for many parents of young children, elements of each may be eclectically integrated in a personal perspective that only occasionally gives rise to feelings of conflict, and that embraces both mutual tolerance and expectations of progressive coordination or fusion.

\section{Historical Change}

Variation in beliefs and practices relating to childrearing and education has been documented not only across contemporary societies and sociocultural groups, but also within a single society over the course of time. Even the concept of childhood has been described by some theorists as "a cultural invention" (Aries, 1962; Kessen, 1979; James \& Prout, 2003). Acknowledgment of the importance of history for an understanding of child development is often credited to Vygotsky (1978). But, as Scribner (1985) observed,

Culture-Sensitive Communication in

Applied Developmental Research
In Vygotsky's theory, [general] history appears as a single unidirectional course of sociocultural change. It is a world process that informs us of the genesis of specifically human forms of behavior and their changing structures and functions in the past. For Vygotsky's model-building purposes, it might have been sufficient to look back at history and view it this way as one stream of development. But for purposes of concrete research, and for theory development in the present, such a view seems inadequate.... Individual societal histories are not independent of the world process, but neither are they reducible to it. To take account of this plurality, the Vygotskian framework needs to be expanded to incorporate a "fourth level" of history - the history of individual societies. (pp. 138-139)

Simplifying parallels between ontogenetic change and secular societal change have been a recurrent source of theoretical confusion in Western philosophy and social science. Major ideological debates have focused on the question of whether any coherent directionality can be detected over the course of human history and if so, what are its key parameters. The notion of societal development that pervades much of contemporary discourse on international development prioritizes certain macroeconomic factors as indicators of a complex, multidimensional process of diachronic change, generating a loosely conflated analogy with ontogenetic change. The category of "developed" nations draws on this analogy to represent societies with industrially accumulated material wealth as more mature than societies without such wealth. Conversely, societies with less industrialization are misrepresented with the designation "under-developed" or "developing" nations implying that they are immature or childlike. On the secular scale of change there is no genuine equivalent to the biological process of maturation. Modernization is a very different kind of change from ontogenesis which is driven by the capacity for reproduction. While economists point to progressive societal trends mediated by the refinement and expansion of labor-saving efficiencies in production, political philosophers note the concurrent emergence of unprecedented potential for destruction of the human species.

Two widely acknowledged indications of a unidirectional process of progressive social change in the world are the establishment in the 20th century (CE) of international fora (notably the United Nations, UN) designed to resolve conflicts peacefully, and of various international agencies to negotiate and refine enduring agreements designed to promote and sustain international cooperation. The concept of globalization is proposed by optimists as an overarching conceptual framework for the next effort to chart a unidirectional pathway for all societies to follow, leveraging the objective fact that we all inhabit the same planet (Kashima, 2016; Sanson \& Burke, 2020).

Human Development 2020;64:222-237 
But the logic applied by international agencies to gather and interpret evidence on how best to operationalize and monitor commitments to abstract common goals such as sustainable development remains a matter of contention. Since the 1990s, the United Nations Development Programme has adopted the Human Development Index as a way of categorizing nations that expands the notion of development beyond the classical economic measure of income (GDP per capita) to include health (represented by life expectancy) and education (represented by literacy and school enrollment), and more recently adjusted to take account of inequality in distribution of wealth (United Nations Development Programme, 2019). While these refinements are grounded in significant philosophical considerations (e.g., Sen, 1999), the UN system's adherence to the notion that societal progress can be meaningfully assessed along a single unidirectional continuum tends to obscure the relation between ontogenesis and secular social change.

For instance, growth of access to education is often indexed by proportion of children enrolled in IPBS, a contemporary world-wide paradigm characterized by "(1) systematic preparation in advance as against giving minimal help at the time when needed, and (2) institutionally authorized competence as against competence needed for practical problem-solving" (Serpell \& Hatano, 1997, p. 367). The paradigm is generally implemented through a curriculum that is institutionally structured in terms of age-graded instruction. Historically,

it took about five centuries for a gradual consensus to emerge among the professional educators and the upper middle classes of European society that children's minds develop along a course from vulnerable innocence to maturity that can be charted in a stepwise fashion corresponding to grades of instruction. (Serpell, 1995, pp. 26-27)

The notion that there is an optimal age for each grade of the basic educational curriculum has infused the practices of intellectual assessment in most modern Western societies, giving rise to stigmatization of adult literacy learners (Freire, 1974) and misrepresentation of children of social groups with economically constrained access to schooling as lacking in intelligence (Serpell, 1993). This distorted theorization has been responsible for legitimizing a popular but oversimplified equation between attaining formal educational credentials and ontogenetic realization of cognitive potential.

The international diffusion of the IPBS paradigm has been mediated by various historical pathways. Political authorities in the USA and in Japan adopted a strategy of deliberate import and adaptation of European educational practices. But in Africa, Christian missionaries and colonial administrators in the 19th-20th centuries exported the Western institution of schooling with a mixture of motives that have been debated in the historical literature, resulting in hegemonic imposition and an extractive definition of educational success that "combines a metaphor of the individual's developmental progress as climbing a staircase with a conception of the social function of schooling as the recruitment of an elite by gradually extracting them from humble origins into a privileged upper class" (Serpell, 1999, p. 115). The globally distributed paradigm of IPBS is thus not so much an example of species-specific adaptation (Packer \& Cole, 2019) as evidence of path dependency in the endurance of human institutions (David, 1994).

While the proliferation of IPBS is at best a weakly conceptualized programmatic implementation of a universally agreed upon societal goal of education, global historical changes with respect to the goal of personal liberty are more encouraging. In the 5th century BCE, the seminal Athenian construct of democracy was superimposed on institutionalized slavery. The Parliamentary revolution in 17th century CE England revived and adapted the concept, but accorded franchise only to male citizens and retained a restricted governing role for the hereditary monarch. In the 18th century CE, the Constitution of the United States declared universal human rights but restricted them by gender and race. Likewise, colonial government by European powers in Asia and Africa in the 18th-19th centuries CE confined civic rights to the colonizer's "master race." Revolutionary reforms in the 19th and 20th centuries led to the abolition of slavery in Britain and the USA, the emancipation of women and the end of the British empire. In 1948, in the wake of the Second World War, the UN adopted a universal declaration of human rights (United Nations, 1948), drafted by a multinational committee of representatives from the USA, UK, France, Canada, Australia, USSR, China, Lebanon and Chile. The declaration was widely invoked by champions of decolonization in Africa, followed by the end of apartheid in South Africa, and by the civil rights movement in the USA to implement the constitutional promise of emancipation. The movement for legal protection of freedom of sexual orientation may be the next phase of this macrohistorical, worldwide consensusbuilding process of legitimizing civil liberties.

Attempts to formalize a similar consensus have achieved at least token endorsement in the nearly universal ratification of the United Nations Convention on the Rights of the Child (UNCRC), adopted by the UN in 1989. But voices of dissent have been raised, suggesting 
that the consultative processes adopted for building consensus may have fallen short of the ideal speech situation postulated by Habermas. Indeed, Bissell et al. (2006) point to a "narrowing effect of ethnocentrism" (p. 12) in the formulation of children's rights in the UNCRC. As a corrective, a separate African Charter on the Rights and Welfare of the Child (ACRWC; UNICEF, 1990) was adopted by the African Union, and, as Kjørholt (2019) notes, there are "basic differences between the CRC and the ACRWC regarding perspectives on children, family life and notions of childhood" (p. 30).

\section{Situating Ontogenesis within Secular Sociocultural Change}

The developmental niche "conceptualization at the interface of child and culture" (Super \& Harkness, 1986) postulates three dimensions of cross-cultural variation: the physical and social settings of a particular ecocultural niche, child-rearing customs, and the psychological thinking and behavior of the child's primary caregivers, forming a coherent system of enculturating child development. Harkness and Super (1992) "assign a leading role to parental ethnotheories of child behavior and development (part of the third component of the niche)," arguing that the "assumptions and values in ethnotheories themselves provide a frame of reference within which parents make decisions about how to socialize their children [including] the ways that parents assign their children to different kinds of physical and social settings" (p. 374).

However, a given cultural group's developmental niche is part of a chronosystem (Bronfenbrenner, 2005) that changes over the course of history. Interaction of changes over the biological life of an individual with secular changes in society complexifies our understanding of how parents' ethnotheories influence the psychological development of their children. Moreover, the individual formulates a personal narrative account of his or her own life course: an autobiographical "life history as a story that is continually revised over time, and with age" (Cohler, 1991, p. 205). The narrator's interpretation of events and processes within that story changes as a function of his or her accumulation of knowledge and shifting personal preoccupations.

As Erikson (1959) famously observed, the ontogenetic period of late adulthood tends to foreground the developmental task of retrospection, in search of integration. Looking back at my own childhood through a sociocultural-historical lens, I struggle to construct a coherent and honest narrative that makes sense of certain vivid, frag-

Culture-Sensitive Communication in

Applied Developmental Research mentary recollections of particular events and episodes. Their emotional intensity prompts me to interpret and evaluate the personal beliefs, attitudes and practices of my parents as well as my own responses to their programmatic attempts to raise me as a knowledgeable, tolerant and responsible person. As a child, I took for granted the validity of my parents' values (kindness, generosity, rationality and tolerance) and judged my own and other's behavior in terms of them. Only in adolescence did I begin to recognize that those values were not universally shared by all adult human beings. And only in adulthood did I seek to understand systematically why individuals and groups who do broadly share them nevertheless come up with such diverse and seemingly incompatible ways of applying them in their ostensible behavior.

An important ingredient of my middle-class English parents' strategic socialization of my elder sister and me fits the description of "assign[ing] their children to different kinds of physical and social settings" (Harkness \& Super, 1992, p. 374). They enrolled us both in the French Lycée in London where we acquired fluency in the French language and familiarity with French culture and history. They also took us with them on holidays in France and sent us individually for holiday visits embedded in families of other European societies. A singular event that stands out among my recollections of childhood took place in a German family home that I visited in the summer of 1953 as a 9-year-old child. I will describe it first within its proximal context. Due to my generally uncomfortable relationship with my host family (I did not get on well with either of the children), a decision was taken that, when my hosts went off on a holiday trip to the countryside, I would stay behind in their city apartment with their housekeeper acting in loco parentis. The particular conversation that I recall as a vivid learning experience took place between me and this temporary caregiver, whom I was shadowing as she went about her daily chores. We were standing in front of the bathroom washbasin and she said something (in German) to the effect that Mr. Stein (pseudonym) was "a dirty man," the ostensible evidence being his habit of not rinsing the washbasin after shaving. I derived two prescriptive messages from this: one practical "When I grow old enough to shave, I should always rinse the basin after using it," the other more general and moral "I should think about the consequences of my actions for others and try to be considerate."

Looking back with a more elaborate understanding of the sociocultural context, I realize now that my caregiver's moral injunction was probably informed by an attitude that I strongly oppose, and probably would have re- 
jected even then at the age of 9 had I been aware of it. My hosts were Jewish and their housekeeper was not. Part of the hostility encoded in her description of her employer as a dirty man was probably informed by a stereotype, actively promoted by Nazi propaganda and still prevalent in immediately postwar Germany, of Jews as culturally deficient and antisocial. But my ignorance of the wider societal context deprived me of understanding that and rendered me vulnerable to influence by a misguided adult in a narrowly construed context.

Interpreting this personal experience requires me to consider the intersection of sociocultural change over the course of history with ontogenetic change in the lives of several protagonists. Tolerance was an explicit moral theme of my early socialization, focused mainly on diversity of language and religious faith. But there was a stark disjunction between my experience as a child and political awareness of any link between my parents' ethnotheories and the dynamic sociocultural context of the event. The explanation of my holiday abroad at the age of 9 was simply to stay with friends of my parents. Not until many years later did I learn that their friendship had been developed during the war, when the Steins were refugees in England, escaping from the Holocaust. My interpretation now of the assumptions and values that framed my parents' decision to assign me to the setting of that family in postwar Germany is that they wanted me to discover at first hand that Germans were normal people not defined by the hostilities between their governments. But, due to the absence of explicit political orientation, my actual experience had the potential to trigger a very different developmental outcome.

I do not contend that my personal interpretations, past or present, built into this fragment of my narrative life course are objectively valid. But I am sure that they have influenced my self-concept and decisions about how to act over the years and thus add to an understanding of my personal life journey, situating it among the many transactions between me and significant others such as my parents, sibling and children, that are in turn embedded in a complex sociocultural system with temporal as well as spatial parameters.

\section{Prospects for Socioculturally Responsive Programming of Early Childhood Care and Education in Africa}

The interface between early childhood development and sociocultural change over the course of history is mediated by systemic relationships at multiple levels. The extent to which international consensus-building on the definition of sustainable development goals reflects and informs the actual practices of caregivers, families and communities depends in large part on the quality of crosscultural communication among various types of stakeholder. At one point in the history of efforts to strengthen the relationship between researchers and policymakers, much emphasis was placed, on the one hand, on ensuring that scientists explained the implications of research findings in a manner that is intelligible to policymakers, while on the other hand, on ensuring that policymakers exercised quality control in the implementation of those implications by designing explicit action plans and monitoring the fidelity with which those plans were executed (Eldering \& Leseman, 1999). More recently, it has become apparent that gaps between theory and practice arise not only from misunderstandings of science by policymakers and/or inefficiency of implementation practices, but also from systematically different preoccupations of the two types of stakeholders (Tabak et al., 2012). Furthermore, at least two other types of stakeholder influence the degree to which the implications of research are played out in the practices of child-rearing, care and education that impact child development outcomes. These are professional practitioners and various authorities in the community of which children and their families are members.

Figure 4 illustrates how members of each of these four types of group share certain "funds of knowledge" (Moll et al., 2005), including collective representations, and also certain occupational statuses, located within an organizational base (Serpell, 2017). In most direct, continuous contact with young children are their parents and families within a local community that also includes traditional elders and community leaders. Important funds of knowledge for this stakeholder group include cultural practices informed by caregiving ethnotheories shared among parents, other family members and traditional elders, some of which are grounded in indigenous cultural traditions while others arise from dynamic interaction between those traditions and ideas promoted by various local organizations such as religious institutions, economic development agencies and political groupings.

Into this local community niche two other stakeholder groups enter with somewhat differing social objectives. On the one hand, researchers enter the field in search of data to inform developmental science, typically with a professional background of training in one or more academic disciplines (such as biology, psychology, anthropology or history). They bring with them specialized funds of knowledge that arise from dynamic interaction 


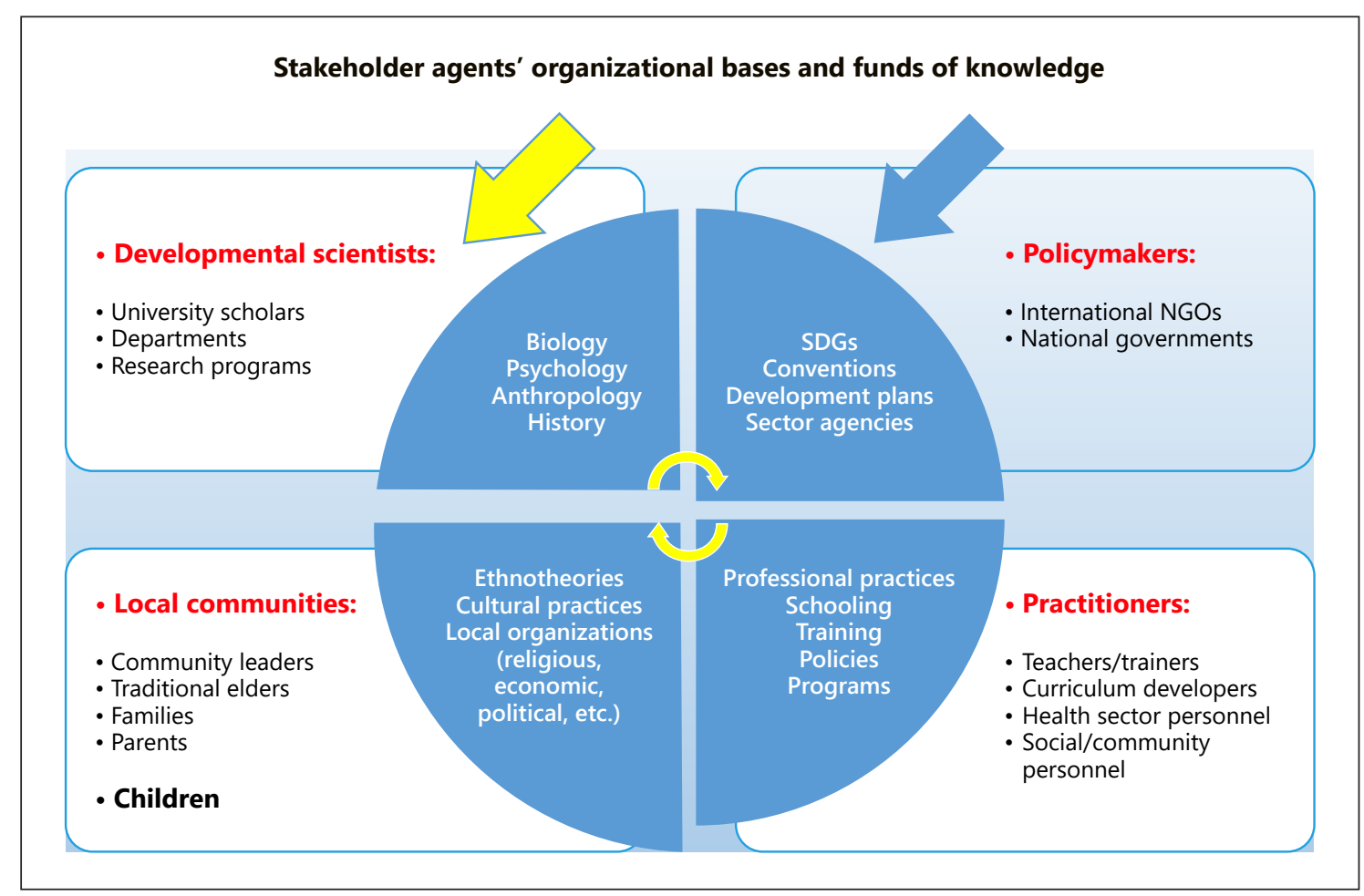

Fig. 4. Multiple ECDCE stakeholder funds of knowledge. SDG, Sustainable Development Goal; NGO, nongovernmental organization.

among various systems of knowledge grounded in academia. Their interactions with young children include direct observation and experimentation, alongside interviews and discussions with adults in the local community.

On the other hand, professional practitioners enter the community with a mission to provide services to young children and the families responsible for their hands-on care. Their funds of knowledge arise from professional training. Sometimes that training is delivered by members of the developmental science stakeholder group with some hands-on field research experience. But more often it is delivered by dedicated training personnel with expertise certified by an institution of higher education, grounded in academic knowledge and sometimes combined with field experience of professional service delivery. These professional personnel are most often accountable to an organization with a service delivery focus on particular types of community need, such as maternal and child health, nutrition, community development, social protection, special education or ECE. Depending on their employer's program description, these professional practitioners may be introduced to the local community as nurses, teachers or social welfare/community development personnel.

Culture-Sensitive Communication in

Applied Developmental Research
Each of those fields of service is informed by policy guidelines, often concretized in the form of an agency's mission and objectives, derived from the fourth stakeholder group designated in Figure 4 as policymakers. Administratively based in organizations such as government departments, international or national NGOs, policymaking stakeholders are actively engaged in designing strategic approaches to intervention on behalf of young children, including service programs channeled to local communities through professional personnel. Their funds of knowledge include secondary analysis of research findings from the various branches of developmental science, as well as policy analysis grounded in national and international processes of a political and economic nature. They advocate and support processes of curriculum development and instruction for training professional personnel to offer appropriate services for promotion of optimal child development.

Because of the differences of perspective across these four types of stakeholder groups, there is a danger that, rather than engaging in cooperative communication, they may talk past each other or only rhetorically acknowledge one another's interests and concerns. A noto- 
riously controversial example is the case of the USA early childhood intervention program Headstart (Beatty \& Zigler, 2012). If the multiple stakeholder groups described above are to successfully generate effective and sustainable enhancement of young children's developmental opportunities, efforts will be needed to foster respectful coconstruction at their various interfaces. But the power relations between their organizational bases are typically asymmetrical, with policymakers exercising powerful control over both the professional terms of reference for practitioners and the curriculum of their training. The research-ethical principles of beneficence and nonmaleficence (American Psychological Association, 2017) and of mutual responsibilities (Society for Research in Child Development, 2007) are often subsumed in intervention studies with children under attribution of authority to representatives of service organizations, leading to questionable arrangements for securing informed parental consent (Kalyanpur \& Harry, 2012). Once a program has been designated as acceptable and adopted by a powerful implementing agency, it typically acquires a momentum of its own that is quite insensitive to critical feedback from individual service recipients (designated in the program as "beneficiaries").

Much of the motivation of parents in Africa for enrolling young children in ECE programs stems from the belief that what children learn there will provide them with a "head start" on formal schooling in grade 1. Moreover, many studies have focused on documenting such benefits (e.g., Mwaura et al., 2008; Martinez et al., 2012; Hall et al., 2013). Because many parents in rural African communities have had limited (and often ambivalent) experience themselves of formal schooling, they tend to regard the curriculum as somewhat culturally alien (Serpell, 1993). But the majority opt for exposing their children to it, trusting that it has the potential to impart useful skills and certification that could open doors for their children to attain an economic quality of life superior to that available to youths without such skills. Underpinning that trust is an implicit worldview that privileges Western culture, language and technology over those endogenous to Africa. Thus, in Zambia and many other African countries, parents often explicitly demand that their children enrolled in ECE programs be provided with opportunities to learn the language of the Western power that continues to dominate the economic and technological spheres across the world.

This widespread, enduring aspiration by parents in a postcolonial state for the youth to acquire competence in the language of the former colonial power can be inter- preted as paradoxical or realistic (Rassool, 2013), as economically progressive or socially divisive (Williams, 2013). The challenge for curriculum developers and policymakers is to design and authorize professional ECE practices that enrich the learning opportunities for young children without alienating them from the positive sociocultural traditions of their home communities. One resource for a more balanced dialogue along the lines of Figure 4 is Akinsola's (2011) account of the indigenous concept of Omoluwabi as an overarching rationale for a holistic approach to education among the Yoruba of western Nigeria. The indigenous Yoruba educational goal of Omoluwabi is to form a complete human person of good character, as shown by respect of old age, loyalty to parents and local traditions, as well as by honesty, duty, sociability, courage and readiness to assist and to work. Another resource is Ng'asike's (2014) articulation of indigenous concepts and traditional economic practices among the Turkana of northern Kenya. Coconstructive application of such dialogue is fundamental to the generative curriculum model advocated by Pence and Ball (1999) and by Nsamenang and Tchombe (2011).

\section{Conclusion}

My central theme in this paper has been that communication, rather than generalization, should be the primary epistemological goal of developmental research. Habermas (1984) drew on Piaget's concept of decentration to articulate what he considered "some characteristics of the mythical and the modern ways of understanding the world" (p. 43). Discussing the issue of how the background convictions underpinning a cultural tradition relate to "communicatively achieved understanding" (p. 70), he stipulated certain properties of a cultural tradition as essential prerequisites "if rational action orientations are to be possible in a lifeworld interpreted correspondingly if they are to be able to consolidate into a rational conduct of life" (p. 71). His vision of a culture conducive to what I have termed "progressive social change" includes several requirements: a metalanguage for differentiating objective, social and subjective worlds; a reflective relation to itself that permits, in principle, interpretations stored in the tradition to be subjected to critical revision; professionally secured subsystems to institutionalize in society specialized learning systems for such critical reflection; and partial institutionalization of purposive-rational action for economic and administrative goals without recourse to perpetual renewal of com- 
municative efforts at understanding. Viewed optimistically, that vision might be attainable through mediumterm incremental reforms in societies with powerfully established institutions integrated into the daily life of most citizens. In Majority World societies, it remains unclear whether legislation introduced through a democratically representative process can secure widespread consensus on the need for change even in ostensibly abusive child-rearing practices such as female genital cutting (Shell-Duncan et al., 2013).

Participatory appropriation of new practices requires strong linkages between old and new understandings; successful co-construction by diverse stakeholder groups requires both common ground and agreed modes of interaction, and sustainable policy requires institutional transformation. Learning how to achieve those preconditions is a task for multidisciplinary collaboration. Research in the Western tradition of the natural sciences tends to construe generalization as the ultimate goal. But that may not be realistic or appropriate for research aimed at improving the quality of communication about human experience, behavior and development among humans with different preoccupations grounded in their immediate context and collective histories. True, we all inhabit the same physical planet, but our niches within it vary greatly, and our understanding of the best interests of our children is deeply infused with implicit theories that emerge from local interactions with others and from particular local histories.

\section{Acknowledgment}

The motivation of this paper derives in significant ways from the influences of my mother, Estelle Agnes Serpell and my father, Michael Friend Serpell. The love and respect I still feel for them, long after their death, are grounded not only in gratitude for their protective and generous kindness, but also in admiration for their consistent nurturance of reflective analytical discourse within our nuclear family, calling into question the rational and moral justification of different opinions.

I am grateful to Profs Ashley Maynard and Nandita Chaudhary for the invitation to present the first draft of this paper at the meeting of the Jean Piaget Society in Portland, OR in June 2019, and for including me in their proposal for this special issue of the journal, Human Development. My international travel and accommodation for the Portland conference were financed by the Jean Piaget Society.

\section{Statement of Ethics}

This article draws on several of the author's studies with children and adults in various societies. Where applicable, compliance with ethical guidelines was affirmed in the cited publications emanating from each study. The paper advances new, integrative interpretations of research by the author and by others, but does not present any new data.

\section{Conflict of Interest Statement}

The author is not aware of any conflict of interest influencing the content of this article.

\section{References}

Adair, J. G., Coêlho, A., \& Luna, J. R. (2002). How international is international psychology? International Journal of Psychology, 37(3), 160$170 . \quad$ https://doi.org/10.1080/ 00207590143000351

Akinsola, E. F. (2011). "Omoluwabi’s approach" to educating the African child. In A. B. Nsamenang \& T. M. Tchombe (Eds.), African educational theories and practices: A generative teacher education handbook (pp. 221-232). Yaoundé, Cameroon: Human Development Resource Centre/Presses Universitaires d'Afrique.

American Psychological Association (2017). Ethical principles of psychologists and code of conduct. Retrieved from https://www.apa. org/ethics/code/ethics-code-2017.pdf

Apple, M. W. (1979). Ideology and curriculum. Abingdon, UK: Routledge. https://doi.org/ $10.4324 / 9780203241219$

Aries, P. (1962). Centuries of childhood (R. Baldick, transl.). London, UK: Jonathan Cape.
Azuma, H. (1984). Psychology in a non-western country. International Journal of Psychology, 19(1-4), 45-55. https://doi.org/10.1080/ 00207598408247514

Beatty, B., \& Zigler, E. (2012). Reliving the history of compensatory education: Policy choices, bureaucracy, and the politicized role of science in the evolution of Head Start. Teachers College Record, 114(6), 1-10.

Bissell, S., Boyden, J., Cook, P., \& Myers, W. (2006). Rethinking child protection from a rights perspective: Some observations for discussion. Hillside Victoria, BC: The International Institute for Child Rights and Development.

Bronfenbrenner, U. (2005). Interacting systems in human development. Research paradigms: present and future (1988). In U. Bronfenbrenner (Ed.), Making human beings human: Bioecological perspectives on human development (pp. 67-93). Thousand Oaks, CA: Sage Publications.
Cohler, B. J. (1991). The life story and the study of resilience and response to adversity. Journal of Narrative and Life History, 1(2-3), 169-200. https://doi.org/10.1075/jnlh.1.2-3.06lif

Dasen, P. R. (1972). Cross-cultural Piagetian research: A summary. Journal of Cross-Cultural Psychology, 3(1), 23-40. https://doi.org/ 10.1177/002202217200300102

Dasen, P. R. (Ed.). (1977). Piagetian psychology: Cross-cultural contributions. New York, NY: Gardner (Halsted/Wiley).

David, P. A. (1994). Why are institutions the "carriers of history"?: Path dependence and the evolution of conventions, organizations and institutions. Structural Change and Economic Dynamics, 5(2), 205-220. https://doi.org/ 10.1016/0954-349X(94)90002-7

Ejuu, G. (2012). Cultural and parental standards as the benchmark for early learning and development standards in Africa. International Journal of Current Research, 4(4), 282-288.
Culture-Sensitive Communication in

Applied Developmental Research 
Eldering, L., \& Leseman, P. (Eds.) (1999). Effective early intervention: Cross-cultural perspectives. London, UK: Falmer.

Enriquez, V. G. (1992). From colonial to liberation psychology: The Philippine experience. Quezon City, Philippines: University of the Philippines Press.

Erikson, E. H. (1959). Identity and the life cycle: Selected papers. New York, NY: International Universities Press.

Freire, P. (1974). Education for critical consciousness. New York, NY: Seabury Press.

Gadamer, H. G. (1965). Truth and method. New York, NY: Sheed \& Ward.

García, O., \& Wei, L. (2018). Translanguaging. The Encyclopedia of Applied Linguistics (pp. 1-7). Hoboken, NJ: Wiley \& Sons. https://doi. org/https://doi.org/10.1002/9781405198431 wbeal1488

Gumperz, J. J. (1982). Discourse strategies. Cambridge, UK: Cambridge University Press. https://doi.org/10.1017/CBO9780511611834

Habermas, J. (1975). Legitimation crisis (T. A. McCarthy, transl.). Boston, MA: Beacon Press.

Habermas, J. (1984). Theory of communicative action: Reason and the rationalization of society (Vol. 1). (T. A. McCarthy, transl.). Boston, MA: Beacon Press.

Hall, J., Sylva, K., Sammons, P., Melhuish, E., Siraj-Blatchford, I., \& Taggart, B. (2013). Can preschool protect young children's cognitive and social development? Variation by center quality and duration of attendance. School Effectiveness and School Improvement: An International Journal of Research. Policy \& Practice, 24(2), 155-176. https://doi.org/10.1 080/09243453.2012.749793

Harkness, S., \& Super, C. M. (1992). Parental ethnotheories in action. In I. E. Sigel, A. V. McGillicuddy-DeLisi, \& J. J. Goodnow (Eds.), Parental belief systems: The psychological consequences for children (2nd ed., pp. 373 392). Hillsdale, NJ: Erlbaum.

Harré, R., Moghaddam, F. M., Cairnie, T. P., Rothbart, D., \& Sabat, S. R. (2009). Recent advances in positioning theory. Theory \& Psychology, 19(1), 5-31. https://doi.org/ $10.1177 / 0959354308101417$

Henrich, J., Heine, S. J., \& Norenzayan, A. (2010). The weirdest people in the world? Behavioral and Brain Sciences, 33(2-3), 61-83. https:// doi.org/10.1017/S0140525X0999152X

Horton, R. (1982). Tradition and modernity revisited. In M. Hollis \& S. Lukes (Eds.), Rationality and relativism (pp. 201-260). Oxford, UK: Blackwell.

James, A., \& Prout, A. (2003). Constructing and reconstructing childhood: Contemporary issues in the sociological study of childhood. London, UK: Routledge. https://doi.org/ 10.4324/9780203362600

Kagitcibasi, C. (1996). Family and human development across cultures: A view from the other side. Hillsdale, NJ: Erlbaum.

Kalyanpur, M., \& Harry, B. (2012). Cultural reciprocity in special education. Baltimore, MD Brookes.
Kashima, Y. (2016). Culture and psychology in the 21st century: Conceptions of culture and person for psychology revisited. Journal of Cross-Cultural Psychology, 47(1), 4-20. https://doi.org/10.1177/0022022115599445

Kessen, W. (1979). The American child and other cultural inventions. The American Psychologist, 34(10), 815-820. https://doi.org/ 10.1037/0003-066X.34.10.815

Kjørholt, A. T. (2019). Early childhood and children's rights: A critical perspective. In A. T. Kjørholt \& H. Penn (Eds.), Early childhood and development work (pp. 17-37). Cham, Switzerland: Palgrave Macmillan. https://doi. org/10.1007/978-3-319-91319-3_2

Lukes, S. (1982). Relativism in its place. In M. Hollis \& S. Lukes (Eds.), Rationality and relativism (pp. 261-305). Oxford, UK: Blackwell.

Marfo, K., \& Biersteker, L. (2011). Exploring culture, play, and early childhood education practice in African contexts. In S. Rogers (Ed.), Rethinking play and pedagogy in early childhood education: Concepts, contexts and cultures (pp. 73-86). London, UK: Routledge.

Martinez, S., Naudeau, S., \& Pereira, V. (2012). The promise of preschool in Africa: A randomized impact evaluation of early childhood development in rural Mozambique. World Bank. Retrieved from http://documents.worldbank.org/ curated/en/819111468191961257

Matafwali, B., \& Serpell, R. (2014). Design and validation of assessment tests for young children in Zambia. New Directions for Child and Adolescent Development, 2014(146), 77-96. https://doi.org/10.1002/cad.20074

Mazrui, A. A. (1986). The Africans: A triple heritage. Arlington County, VA: Public Broadcasting Service.

McCarthy, T. (1978). The critical theory of Jürgen Habermas. Cambridge, UK: Polity Press.

Moll, C. L., Amanti, C., Neff, D., \& Gonzalez, N. (2005). Funds of knowledge for teaching: Using a qualitative approach to connect homes and classrooms. In N. Gonzalez, L. C. Moll, \& C. Amanti (Eds.), Funds of knowledge. Theorizing practices in households, communities, and classrooms (pp. 71-88). Hillsdale, NJ: Erlbaum.

Mukela, R. M. (2013). The role of indigenous music and games in the promotion of cognitive development in Zambian children in Senanga and Shangombo districts of Western Province [Master's thesis], University of Zambia. UNZA Repository. Retrieved from http:// dspace.unza.zm/

Mwaura, P. A., Sylva, K., \& Malmberg, L. E. (2008). Evaluating the Madrasa preschool programme in East Africa: A quasi-experimental study. International Journal of Early Years Education, 16(3), 237-255. https://doi. org/10.1080/09669760802357121

Ng'asike, J. T. (2014). African early childhood development curriculum and pedagogy for Turkana nomadic pastoralist communities of Kenya. New Directions for Child and Adolescent Development, 2014(146), 43-60. https://doi. org/10.1002/cad.20072
Nsamenang, A. B. (1992). Human development in cultural context: A third world perspective. Atlanta, GA: Sage. https://doi.org/ $10.4135 / 9781483326030$

Nsamenang, A. B. (2006). Human ontogenesis: An indigenous African view on development and intelligence. International Journal of Psychology, 41(4), 293-297. https://doi.org/ 10.1080/00207590544000077

Nsamenang, A.B. \& Tchombe, T.M. (Eds.) (2011). African educational theories and practices: A generative teacher education handbook. Yaoundé, Cameroon: Human Development Resource Centre/Presses Universitaires d'Afrique.

Oppong, S. (2015). A critique of early childhood development research and practice in Africa. Africanus: Journal of Development Studies, 45(1), 23-41. https://doi.org/10.25159/0304$615 \mathrm{X} / 252$

Oppong, S. (2019). Overcoming obstacles to a truly global psychological theory, research, and praxis in Africa. Journal of Psychology in Africa, 29(4), 292-300. https://doi.org/10.1080/ 14330237.2019.1647497

Packer, M. J., \& Cole, M. (2020). The institutional foundations of human evolution, ontogenesis, and learning. In N. S. Nasir, C. D. Lee, R. Pea, \& M. M. de Royston (Eds.), Handbook of the cultural foundations of learning. Abingdon, UK: Routledge. https://doi.org/ 10.4324/9780203774977-2

Pence, A., \& Ball, J. (1999). Two sides of an eagle's feather: Co-constructing ECCD training curricula in university partnerships with Canadian First Nations communities. In H. Penn (Ed.), Theory, policy, and practice in early childhood services (pp. 36-47). London, UK: Open University Press.

Piaget, J. (1970). Piaget's theory. In P. Mussen (Ed.), Carmichael's manual of child psychology (Vol. 1, pp. 703-832). Hoboken, NJ: Wiley $\&$ Sons.

Rassool, N. (2013). The political economy of English language and development: English vs. national and local languages in developing countries. In E. J. Erling \& P. Seargeant (Eds.), English and development policy, pedagogy and globalization (pp. 45-67). Bristol, UK: Multilingual Matters. https://doi.org/10.21832/ 9781847699473-00

Sanson, A. V., \& Burke, S. E. L. (2020). Climate change and children: An issue of intergenerational justice. In N. Balvin \& D. Christie (Eds.), Children and peace. Peace Psychology Book Series. Cham, Switzerland: Springer. https://doi.org/10.1007/978-3-030-221768_21

Scribner, S. (1985). Vygotsky's uses of history. In J. M. Wersch (Ed.), Culture, communication, and cognition: Vygotskian perspectives (pp. 119-145). Cambridge, UK: Cambridge University Press.

Sen, A. (1999). Development as freedom. Oxford, UK: Oxford University Press. 
Serpell, R. (1990). Audience, culture and psychological explanation: A reformulation of the emic-etic problem in cross-cultural psychology. The Quarterly Newsletter of the Laboratory of Comparative Human Cognition, 12(3), 99-132.

Serpell, R. (1993). The significance of schooling: Life-journeys in an African society. Cambridge, UK: Cambridge University Press.

Serpell, R. (1995). Situated theory as a bridge between experimental research and political analysis. In L. Martin, K. Nelson, \& E. Tobach (Eds.), Cultural psychology and activity theory: Essays in honor of Sylvia Scribner (pp. 2142). Cambridge, UK: Cambridge University Press.

Serpell, R. (1999). Local accountability to rural communities: a challenge for educational planning in Africa. In F. Leach \& A. Little (Eds.), Education, cultures and economics: Dilemmas for development (pp. 107-135). New York, NY: Garland.

Serpell, R. (2006). Negotiating the middle ground between the ostensible and shared horizons: A dynamic approach to cross-cultural communication about human development. In J. Straub, D. Weidemann, C. Kölbl, \& B. Zielke (Eds.), Pursuit of meaning: Advances in cultural and cross-cultural psychology (pp. 393433). Bielefeld, Germany: Transcript Verlag. https://doi.org/10.14361/9783839402344017

Serpell, R. (2007). Bridging between orthodox western higher educational practices and an African sociocultural context. Comparative Education, 43(1), 23-51. https://doi.org/ $10.1080 / 03050060601162396$

Serpell, R. (2017, November). Co-constructing participation to enhance the value of developmental science in context: Case studies of ECD interventions in Zambia [Conference presentation]. 2nd International Conference on Early Childhood Development, Institute for Human Development, Dar es Salaam, Tanzania.
Serpell, R. (2018). Perspectivist challenges for ECD intervention in Africa. In A. T. Kjørholt $\&$ H. Penn (Eds.), Early childhood and development work: Theories, policies and practices (pp. 39-68). Basingstoke, UK: Palgrave.

Serpell, R. (2019). Africentric engagement with child development theory and education: The legacy of Bame Nsamenang. International Journal of Behavioral Development, 2, Serial No. 76, 5-7.

Serpell, R. \& Hatano, G. (1997). Education, literacy and schooling in cross-cultural perspective. In J. W. Berry, P. R. Dasen \& T. M. Saraswathi (Eds.), Handbook of cross-cultural psychology (2nd ed., Vol. 2, pp. 345-382). Boston, MA: Allyn \& Bacon.

Serpell, R., \& Mukela, R. M. (2019). Systemic challenges for integration of ECDCE programmes with African cultures of early childhood socialization. In A. Pence \& J. Harvell (Eds.), Pedagogies for diverse contexts (pp. 141-160). Abingdon, UK: Routledge.

Shell-Duncan, B., Hernlund, Y., Wander, K., \& Moreau, A. (2013). Legislating change? Responses to criminalizing female genital cutting in Senegal. Law \& Society Review, 47(4), 803-835. https://doi.org/10.1111/lasr.12044

Shotter, J. (1975). Images of man in psychological research. London, UK: Methuen.

Shweder, R., Mahapatra, M., \& Miller, J. (1990). Culture and moral development. In J. Stigler, R. Schweder, \& G. Herdt (Eds.), Cultural psychology: Essays on comparative human development (pp. 130-204). Cambridge, UK: Cambridge University Press; https://doi.org/ 10.1017/CBO9781139173728.005

Sinha, D. (1997). Indigenizing psychology. In J. W. Berry, Y. H. Poortinga, \& J. Pandey (Eds.), Handbook of cross-cultural psychology: Theory and method (2nd ed., pp. 129-169). Boston, MA: Allyn \& Bacon.

Society for Research in Child Development (2007, March). Ethical standards for research with children. Retrieved from https://www.srcd. org/about-us/ethical-standards-researchchildren
Sternberg, R. J. (2000). Intelligence and wisdom. Cambridge, UK: Cambridge University Press. h t t p s:// d o i.org/10.1017/ CBO9780511807947.029

Super, C. M., \& Harkness, S. (1986). The developmental niche: A conceptualization at the interface of child and culture. International Journal of Behavioral Development, 9(4), 545-569. https://doi.org/10.1177/016502548600900409

Tabak, R. G., Khoong, E. C., Chambers, D. A., \& Brownson, R. C. (2012). Bridging research and practice: Models for dissemination and implementation research. American Journal of Preventive Medicine, 43(3), 337-350. https://doi/org/https://doi.org/10.1016/j. amepre.2012.05.024

Teo, T. (2008). From speculation to epistemological violence in psychology: A critical hermeneutic reconstruction. Theory \& Psychology, 18(1), 47-67. https://doi.org/10.1177/ 0959354307086922

Tobin, J. J., Wu, D. Y., \& Davidson, D. H. (1989). Preschool in three cultures: Japan, China, and the United States. New Haven, CT: Yale University Press.

UNICEF (1990). The African Charter on the Rights and Welfare of the Child. Retrieved from https://www.unicef.org/esaro/African Charter_articles_in_full.pdf

United Nations Development Programme (2019). Human Development Report 2019. Retrieved from http://hdr.undp.org/sites/default/files/ hdr2019.pdf

United Nations. (1948). Universal Declaration of Human Rights. Retrieved from https://www. un.org/en/universal-declaration-humanrights/

Vygotsky, L. (1978). Mind in society: The development of higher psychological processes. Cambridge, MA: Harvard University Press.

Williams, E. (2013). Political perspectives on language policies and development in Africa. In E. J. Erling \& P. Seargeant (Eds.), English and development policy, pedagogy and globalization (pp. 68-87). Bristol, UK: Multilingual Matters. https://doi.org/10.21832/9781847699473-007
Culture-Sensitive Communication in Applied Developmental Research
Human Development 2020;64:222-237 DOI: $10.1159 / 000512192$ 